\title{
Characteristics of patients in a psychiatric follow-up clinic
}

\author{
A. K. SHAH, Senior Registrar, Whittington Hospital, Highgate Hill, London N19; and \\ S. LYNCH, Lecturer in Psychiatry, St Mary's Hospital, London W2
}

Out-patient clinics are widely used to asssess and treat patients. In psychiatric practice, out-patient clinics are used both to assess new referrals and follow up existing patients. More than three-quarters of psychiatric out-patient attendances are for followup (DHSS, 1984). With modern emphasis on community psychiatry, the role of out-patient clinics may become less prominent and more refined. Very little appears to have been published on the subject of psychiatric follow-up clinics.

With this in view, a pilot study looking at the characteristics of patients at a follow-up clinic and the difference between attenders and non-attenders was performed.

\section{The study}

A prospective study for two months (November and December 1988) in a registrar's follow-up outpatient clinic at a London teaching hospital was undertaken. The clinic was held every Thursday morning. All patients booked to attend the clinic were included. The patients being followed up had previously been seen in new out-patient clinics, casualty department, day hospital and in-patient settings. An itemised questionnaire of the characteristics of the patients was completed with the aid of case-notes, interview with the patient (attenders only), and previous personal knowledge of the patient. Fishers exact test, $\chi^{2}$ test and $t$-test were used to analyse the data.

\section{Findings}

During the study period 45 patients had appointments to attend the clinic. Of the 45 study patients, 20 $(44 \%)$ were male and $33(73 \%)$ were unemployed. Only $16(36 \%)$ were married and the mean age was 42.5 years.

Nearly $90 \%(n=39)$ had a diagnosis of either schizophrenia $(58 \%)$ or manic depressive psychosis $(29 \%)$ and $90 \%$ had at least one previous admission. Moreover, $91 \%$ of the patients were on psychotropic medication. Only $50 \%(n=22)$ of patients were followed-up by other disciplines (social workers, psychologists, community psychiatric nurses, etc.) and only $10 \%(n=5)$ of patients attended any day facility (day centre or sheltered workshop); $90 \%(n=40+)$ appeared to reside in their own homes and only $10 \%$ $(n=5)$ at hostels.

Of the 45 patients booked into the clinic, $17(38 \%)$ did not attend. This is consistent with reports of $20-57 \%$ of general psychiatric out-patients failing to return after the first visit (Baekland \& Lundwall, 1975). There were no statistically significant differences between attenders and non-attenders in terms of age, sex, marital status, employment, diagnosis, previous deliberate self-harm, previous psychiatric history, psychotropic medication, attendance at day centres, follow-up by other disciplines and accommodation. Previous history of non-attendance was over represented in the non-attender group $\left(\chi^{2}=\right.$ 4.44, id.f., $P<0.05$ ).

\section{Comment}

The majority $(87 \%)$ of the patients had a diagnosis of either schizophrenia or manic depressive illness. Patients with both these diagnoses are liable to chronicity and recurrent relapse, and this explains the previous admission rate of $90 \%$. In contrast to these findings, in a study of new out-patients, depression and personality disorder accounted for the majority of diagnoses (Johnson, 1973). Patients with schizophrenia and manic depressive illness are likely to be on psychotropic medication and hence attend the clinic for medication. This is supported by the higher rate of psychotropic medication being prescribed.

Another surprising finding was only $10 \%$ of patients attended any day facility in addition to the $27 \%$ employed. This may partly reflect the lack of day facilities in the catchment area of the hospital. Similarly, the poor provision of hostel facilities in the catchment area of the hospital may reflect only a small number of patients residing in hostels $(10 \%)$.

This study was unable to identify any predictive factors of non-attendance except previous history of non-attendance. This finding is consistent with Frankel et als (1989) conclusion that client factors are not important in predicting and explaining failed attendances in new out-patient clinics. 
A larger prospective study with formal follow-up of non-attenders in a psychiatric follow-up clinic would produce invaluable data.

\section{References}

BaEKLAND, F. \& Lundwall, L. (1975) Dropping out of treatment. A critical review. Psychological Bulletin, 82, 738-783.
Department of Health and Social Security (1984) The facilities and services of mental illness and mental handicap. Hospitals in England (1977-79). Statistical and Research Report No. 26. London: HMSO.

Frankel, S., Farrow, A. \& West, R. (1989) Nonattendance or non-invitation? A case control study of failed out-patient appointments. British Medical Journal. 298, 1343-1345.

JoHnson, D. A. W. (1973) An analysis of out-patient services. British Journal of Psychiatry, 22, 301-306.

\title{
The absconder and the Hospital Order
}

\author{
ADERSH KAUL, Registrar in Forensic Psychiatry, Towers Hospital, Leicester LE5 0TD; \\ and MAGGIE WHITTAKER, Senior Social Worker, Broadmoor Hospital, Crowthorne, \\ Berkshire RG11 7EG
}

The Mental Health Services have been accused of providing a 'soft option' to offenders and this charge is highlighted in cases where the mentally disordered offender absconds (hereafter called the absconder) from the hospital. Society just about manages to accept the disposal of disturbed offenders to hospital, which it sees as providing at least some limited incarceration, but in the event of an offender absconding the whole dilemma of offenders considered to be in need of treatment is thrown into question. The Responsible Medical Officer (RMO) is concerned with issues of treatment, public safety and his/her responsibility to the Courts and society; and thus finds himself/herself in the conflicting roles of a doctor and an agent of social control. This paper attempts to address some of the issues surrounding the areas of the rights of the patient, the dilemma faced by the clinicians and the rightful use of the powers of the doctor and of the State in relation to Hospital Order and the absconder.

\section{Treatment or punishment}

The Hospital Order is generally considered as a humane alternative to the sentencing of mentally abnormal offenders to prison. It is imposed explicitly for the purpose of treatment rather than punishment and by imposing the Hospital Order the court channels the mentally abnormal offender into the mental health rather than the penal system. The primacy of therapeutic rather than a punitive consideration has been emphasised in a Government White Paper, Department of Health and Social Security (1978) which states "in making the Order the court is placing the patient in the hands of the doctors, foregoing any question of punishment and relinquishing from then onwards its own control over him". Bluglass (1983) reminds us "it is an alternative disposal and the person becomes a patient not a prisoner".

Despite the therapeutic spirit behind the Hospital Order, it is not difficult to see how the deprivation of liberty coupled with treatment without consent may be interpreted as a form of punishment. Potas (1982) points out that the assumption that a Hospital Order is "not punitive is to misconceive the objective of the sanction. It shares with imprisonment the consequence of depriving an individual of his or her liberty. Like imprisonment it offers protection to the community by separating inmates from normal 